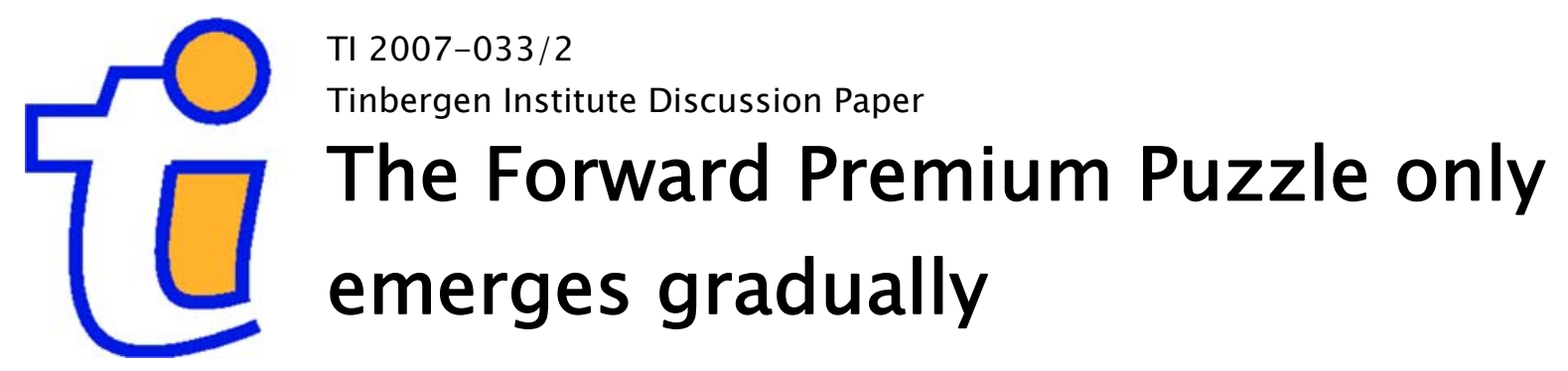

Kerstin Bernoth ${ }^{1,2}$

Jürgen von Hagen',3

Casper G. de Vries ${ }^{4}$

' De Nederlandsche Bank, and ZEI;

2 University of Bonn;

3 Indiana University, and CEPR;

${ }^{4}$ Erasmus University Rotterdam, and TI. 


\section{Tinbergen Institute}

The Tinbergen Institute is the institute for economic research of the Erasmus Universiteit Rotterdam, Universiteit van Amsterdam, and Vrije Universiteit Amsterdam.

Tinbergen Institute Amsterdam

Roetersstraat 31

1018 WB Amsterdam

The Netherlands

Tel.: $\quad+31(0) 205513500$

Fax: $\quad+31(0) 205513555$

Tinbergen Institute Rotterdam

Burg. Oudlaan 50

3062 PA Rotterdam

The Netherlands

Tel.: $\quad+31(0) 104088900$

Fax: $\quad+31(0) 104089031$

Most TI discussion papers can be downloaded at http:/ /www.tinbergen.nl. 


\title{
The Forward Premium Puzzle Only Emerges Gradually*
}

\author{
Kerstin Bernoth ${ }^{\dagger}$ \\ De Nederlandsche Bank and ZEI-University of Bonn \\ Juergen von Hagen $\ddagger$ \\ University of Bonn, Indiana University, and CEPR \\ Casper G. de Vries ${ }^{\S}$ \\ Erasmus University Rotterdam and Tinbergen Institute
}

\begin{abstract}
The forward premium puzzle (FPP) is the negative correlation between the forward premium and the realized exchange rate return at maturities of a month and beyond. Some recent evidence shows that at maturities of multiple years and at the highest intra day frequency the correlation is positive and close to one. This paper contributes by using futures data instead of forwards to complete the maturity spectrum at the (multi-) day level. We find that the correlation only slowly turns negative as the number of days to maturity is increased to the monthly level. The typical shape of the premium correlation with regard to the forward maturity length appears to be V-shaped.
\end{abstract}

JEL classification: F31, F37, G13

Keywords: exchange rates, market efficiency, forward premium puzzle, uncovered interest parity, futures rates

\footnotetext{
${ }^{*}$ The authors thank Jan Marc Berk, the participants of the 50th European Conference of the Econom(etr)ics Community and of the DNB lunch seminar for helpful comments. The opinions expressed in this paper do not necessarily represent the view of De Nederlandsche Bank.

${ }^{\dagger}$ Corresponding author, mail address: DNB, Economics and Research Department, PO Box 98, 1000 AB Amsterdam, The Netherlands, k.bernoth@dnb.nl.

${ }^{\ddagger}$ E-mail address: vonhagen@uni-bonn.de.

$\S$ E-mail address: cdevries@few.eur.nl.
} 


\section{Introduction}

The 'forward premium puzzle' (FPP) is the subject of a large theoretical and empirical literature. It was first described by Fama (1984), who regressed the monthly return on exchange rates on the one month forward premium. According the uncovered interest parity (UIP) condition the coefficient on the forward premium in such regressions should be unity. However, Fama (1984) reported that the estimated slope coefficient is negative instead. Successive studies confirmed this puzzle for a large number of different exchange rates and time periods (compare e.g. Froot and Frankel (1990) and Engel (1996) for an overview). Froot and Frankel (1990) find that the average estimate in over 75 published articles is -0.88 . Taken at face value, it suggests that market participants are not able to correctly predict the direction of exchange-rate changes. In other words, a country with a high interest rate tends to appreciate, instead of depreciate as it would be suggested by the UIP condition.

The literature so far failed to reach a consensus on the reasons for this puzzle. Several explanations have been offered. One branch of the literature argues that the forward premium contains a time-varying risk premium which is negatively correlated with the expected change in the exchange rate (compare e.g. Fama, 1984; Hodrick and Srivastava, 1986; and Hsieh, 1984). Another explanation is that the forward premium contains a systematic forecast error due to e.g. learning about regime shifts, Peso problem or irrational information processing (see e.g. Bilson, 1981; Mark and Wu, 1998; Krasker, 1980; Rogoff, 1985; Evans and Lewis, 1995; Lewis, 1989; Gourinchas and Tornell, 2004.). McCallum (1994) argues that the negative bias appears due to monetary policy interventions in the sense that monetary authorities counter large shocks in exchange rates by changing the interest rate to offset the original shock. In two recent papers, Bacchetta and Wincoop $(2006,2007)$ argue that infrequent FX portfolio revisions and incomplete information processing explain the FPP.

An important aspect of the majority of published studies on the FPP is that they test the expectations hypothesis with medium term data covering maturity horizons ranging from one to twelve months. The reason is that a relatively liquid forward exchange markets exist only for these maturities. Some recent evidence shows that the appearance of this puzzle depends significantly on the observed maturity horizon of financial products. Alexius (2001), Chinn and Meredith (2004) and Chinn (2006) focus on the related UIP condition (UIP) at the multi year maturity level. Using five and ten year zero-coupon yields, they find that the rejection of the UIP becomes less decisive if the maturity horizon increases. ${ }^{1}$ Chaboud and Wright (2005)

\footnotetext{
${ }^{1}$ Similarly, Fama and Bliss (1987) and Fama (2006) test the expectations hypothesis for the forward interest rate market and also confirm that longer-term forward rates have more power to forecast spot interest rates.
} 
reconsider the UIP hypothesis for the shortest maturity horizon possible at the intra day level. They find results that are supportive for the expectations hypothesis over very short maturity horizons up to a day.

Conventionally the expectations hypothesis is tested by using forward exchange rates. The forward rates come only in maturities of one, two, three, six and twelve months. Thus, one is restricted to using monthly horizons and multiples thereof. For foreign exchange futures, however, the shortest time to maturity is a single day. To fill the gap at the (multi-) day maturity level, this paper tests the expectations hypothesis by using foreign exchange futures data. The maturity horizons we consider run from one day, two days, etc., up to three months. We find that the slope coefficient is decreasing with the maturity horizon of the foreign exchange futures. For maturity horizons shorter than one month, the estimated slope coefficient is generally positive, with only a few exceptions. Up to the three weeks maturity horizon the expectations hypothesis is not rejected. Only for maturity horizons longer than one month, we mostly confirm the FPP of a negative slope coefficient. Thus, combining our findings with that of Alexius (2001), Chinn and Meredith (2004), Chaboud and Wright (2005) and Chinn (2006), it appears that the market in the beginning follows the predictions of the expectations hypothesis, but reverses itself, only to come back to this once again after a period of years. All in all we conclude that the typical shape of the premium correlation with regard to the forward maturity length appears to be $\mathrm{V}$-shaped. This finding is new to the existing literature.

We further exploit the information in futures data by investigating the relation between forex returns and forward premium when the horizon of the forex return and the maturity length overlap only partially. Pope and Peel (1991) and McCallum (1994) ran regressions of the change in the (log) exchange rate between $t$ and $t-2$ on the difference between the forward rate at $t-1$ for time $t$ delivery and the spot rate at $t-2$. We interpret these regressions as providing information on the relative importance of news versus forecasts. The slope estimates in such regressions with futures turn out to be close to one, confirming the news dominance feature.

The futures data also allow one to do the reverse and investigate how the forex returns between $t$ and $t-1$ correlate with the difference between the futures rate at $t-2$ for time $t$ delivery and the exchange rate at $t-1$. This in a way asks whether forex returns during the later part of the maturity horizon are moving as predicted by the futures contract signed much earlier. We find that the latter procedure provides some information about the innovations that are responsible for the futures premium puzzle at the monthly horizon. But we also show that this information can be obtained more clearly and directly. Doing just this shows that the daily forex returns start at the beginning of the maturity period by moving in line with the expectations hypothesis, only to move in the opposite direction during the later part of the maturity period. 
The paper proceeds as follows. Section 2 states the FPP and describes the data. Section 3 reconsiders the evidence in terms of the futures premium puzzle. Sections 4 and 5 elicit further evidence form the futures contracts. Section 6 concludes.

\section{The Expectations Hypothesis and Futures Data}

Let $s_{t}$ denote the log of the spot exchange rate at time $t$ and $f_{t-m}^{t}$ be the log of the futures exchange rate at time $t-m$ with delivery for time $t$ and maturity $m$. Following the expectations hypothesis, a futures rate is regarded as an efficient predictor of the spot exchange rate at the maturity date of the futures contract, $t$. To test this hypothesis, realized spot rates are regressed on futures. In view of the non-stationarity of spot and futures exchange rate, one typically does not regress the level of spot exchange rates on the level of futures exchange rate, but transforms the data by subtracting a lagged spot exchange rate from both variables. ${ }^{2}$ If the expectations hypothesis holds, one can write the regression equation as follows:

$$
s_{t}-s_{t-m-k}=\phi+\beta_{(m, k)}\left(f_{t-m}^{t}-s_{t-m-k}\right)+\eta_{t-m} .
$$

The null hypothesis of efficiency is $H_{0}: \phi=0$ and $\beta_{(m, k)}=1$.

The existing literature concentrates almost entirely on using forward exchange rates in estimating equation (1). Moreover, given the modulu one month data, the literature with two exceptions sets $k=0$. Therefore in the next section we first present regressions of the forward premium $f_{t-m}^{t}-s_{t-m}$ on the corresponding change of exchange rate return $s_{t}-s_{t-m}$. Let $y_{t-m}^{t}$ be short notation for the exchange rate innovation $s_{t}-s_{t-m}$ and $p_{t-m}^{t}$ for the forward premium $f_{t-m}^{t}-s_{t-m}$. Then the conventional expectations hypothesis regression, often denoted as the 'Fama regression', is as follows:

$$
y_{t-m}^{t}=\phi+\beta_{(m, 0)} p_{t-m}^{t}+\eta_{t-m},
$$

where the slope coefficient is

$$
\beta_{(m, 0)}=\frac{\operatorname{Cov}\left[y_{t-m}^{t}, p_{t-m}^{t}\right]}{\operatorname{Var}\left[p_{t-m}^{t}\right]} .
$$

Given the characteristics of forward exchange rate contracts, most empirical studies estimate equation (2) for maturity horizons ranging between one and 12 months. The general finding is that the estimated slope coefficient for these maturity horizons is significantly negative and suggests that market participants do not even get the direction of exchange rate changes

\footnotetext{
${ }^{2}$ Evidence for a unit root contained in spot and forward exchange rates is given in e.g. Meese and Singleton (1982), Baillie and Bollerslev (1987) or Clarida and Taylor (1997).
} 
correct. ${ }^{3}$ Thus, the null hypothesis for efficiency is mostly rejected. The negative slope coefficient is the central feature of the so called FPP.

To our knowledge, no study has used futures contracts instead of forward contracts to test the expectations hypothesis. While forward contracts are available only for fixed maturity lengths, i.e. one, two, three, six and twelve months, futures contracts have a fixed maturity date, which is e.g. the third Wednesday of a month. Accordingly, the maturity length is determined by the date, when the futures contract is traded and the maturity spectrum can be measured in daily units. Thus, futures data embody a much finer set of information.

A necessary condition for the comparability of estimation results based on forward contract and futures contracts is that there is no significant difference between forward and futures prices. However, futures and forward contracts differ in the way that futures contracts are traded on official exchanges and require a margin while forwards contracts are usually created by individual parties operating in the decentralized OTC (over the counter) markets. Whether these differences result in a distinguishable spread between forward and futures prices is subject of several studies (as e.g. Cornell and Reinganum, 1981; Polakoff and Grier, 1991; Chang and Chang, 1990 and Hull, 2006). The general finding is that those factors which might cause forward and futures prices to differ, e.g. differences in default risk or liquidity premia, can be ignored and that the two prices are the same. We therefore feel confident using futures data as an alternative to forward data to test the expectation hypothesis. Moreover, at he monthly maturities our futures data generate the same results as the forward data.

Our estimates are based on daily closing spot and 3-month futures exchange rate data for four currencies, i.e. US\$/DM, US\$/Franc, US\$/Pound, and US\$/Yen. The futures contracts have four delivery dates during a year, namely the third Wednesday of May, June, March, and December. We regard futures rates $f_{t-m}^{t}$ with a time to delivery of up to three months, thus, the forecast horizon of the futures rates range between one and 65 working days, thus, $m=1, \ldots, 65$.

Our data set covers US\$/DM futures rates that are priced between 6 September 1990 and 17 December 2001. Thus, we observe 44 different US\$/DM futures contracts, which settle between March 1991 and December 2001. The data set contains 32 different US $\$ /$ Franc futures contracts with delivery between March 1994 and December 2001, and the futures rates are priced between 2 September 1993 and 17 December 2001. The US\$/Pound futures rates are observed between 2 December 1992 to 15 December 2003 for 43 different futures contracts maturing between June 1993 and December 2003. Our data set includes 52 US\$/Yen futures contracts, which settle

\footnotetext{
${ }^{3}$ Compare e.g. Froot (1990), Bekaert and Hodrick (1993), Mark, Wu and Hai (1993), Engel (1996), and Mark and Wu (1998).
} 
between March 1991 and December 2003, and the futures rates are priced between 6 September 1990 and 15 December 2003.

\section{The Expectations Hypothesis at the (multi-) Day Level}

Before estimating equation (2) we test whether we can pool our data of the US\$/DM, US\$/Franc, US\$/Pound, and US\$/Yen futures contracts into one data set in order to increase the number of observations. That means that we test whether the constant terms $\phi$ and also the slope coefficients $\beta_{m, 0}$ are the same for all four currencies. We find that the null hypothesis for poolability cannot not be rejected for all $m=1, \ldots, 65$. As a result, we run our estimations the pooled data set, which consists of 171 observations in total. ${ }^{4}$ Further, Dickey-Fuller tests show that the futures premium and the change of exchange rates satisfy the stationarity condition, so that consistent estimation of equation (2) is feasible.

The estimates show that in all 65 regressions the constant term $\phi$ is not statistically different from zero. The estimates for the slope coefficient $\beta_{(m, 0)}$ and its moving average are plotted in Figure 1 with respect to the maturity length $m$ in days. ${ }^{5}$ We highlight the slope coefficients for the maturity horizons available for forward exchange rates covered by our observed forecast period, i.e. for $m=\{22,43,65\}$, by encircling these particular estimates. This highlights the extra information provided by the futures data.

We observe that the slope coefficient of the conventional test regression for the expectations hypothesis is decreasing with the length of maturity horizon $m$. For futures rates with a time to maturity shorter than one month (less than 22 working days) the estimated slope coefficient is positive with only two exceptions, which is in favor of the expectations hypothesis. Only for maturity horizons longer than one month, we mostly confirm the FPP of a negative slope coefficient. Thus, the expectations hypothesis holds for shorter but not for the medium term maturities. More specifically, if one focusses attention on the maturity horizons that would be available for forward exchange rates (encircled spots in the Figure), one is tempted to reject the expectations hypothesis and to support the FPP. For a maturity length of one month, the slope coefficient is close to zero. For the two- and three-month maturity, however, $\beta_{(m, 0)}$ is negative and close to the value of -1 .

\footnotetext{
${ }^{4}$ The estimation results for the individual currencies are available on request.

${ }^{5}$ In Figure 3 we plot only the maximum and minimum value across $m=1, \ldots, 65$ for every value of $k$. Here, we plot all estimated slope coefficients with fixing $\mathrm{k}$ to zero for $m=1, \ldots, 65$.
} 


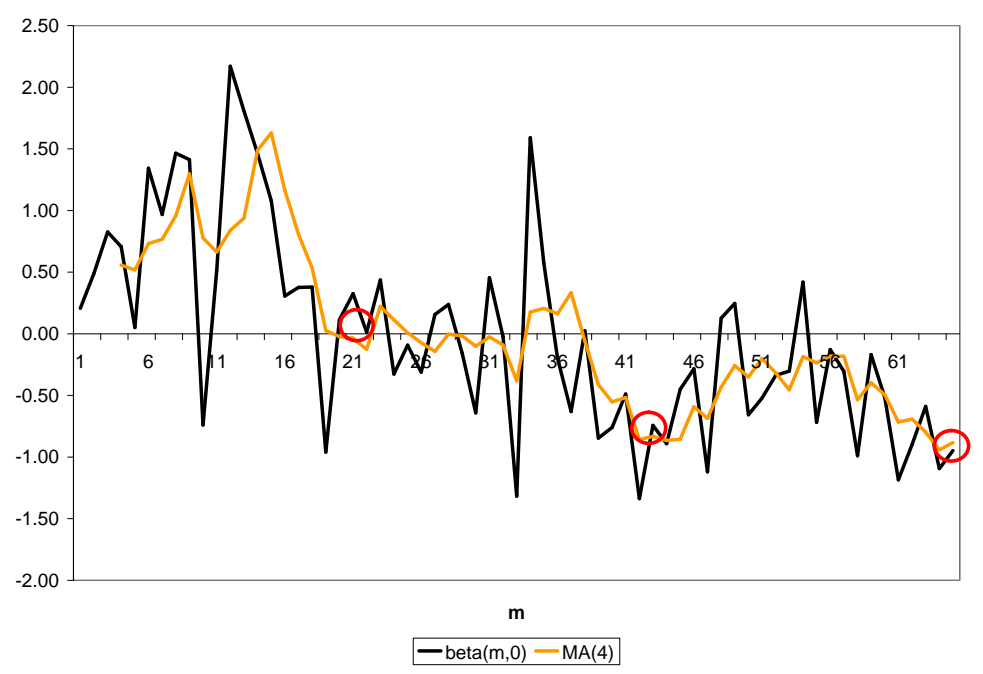

Figure 1: $\beta_{m, 0}$ for $m=1, \ldots, 65$

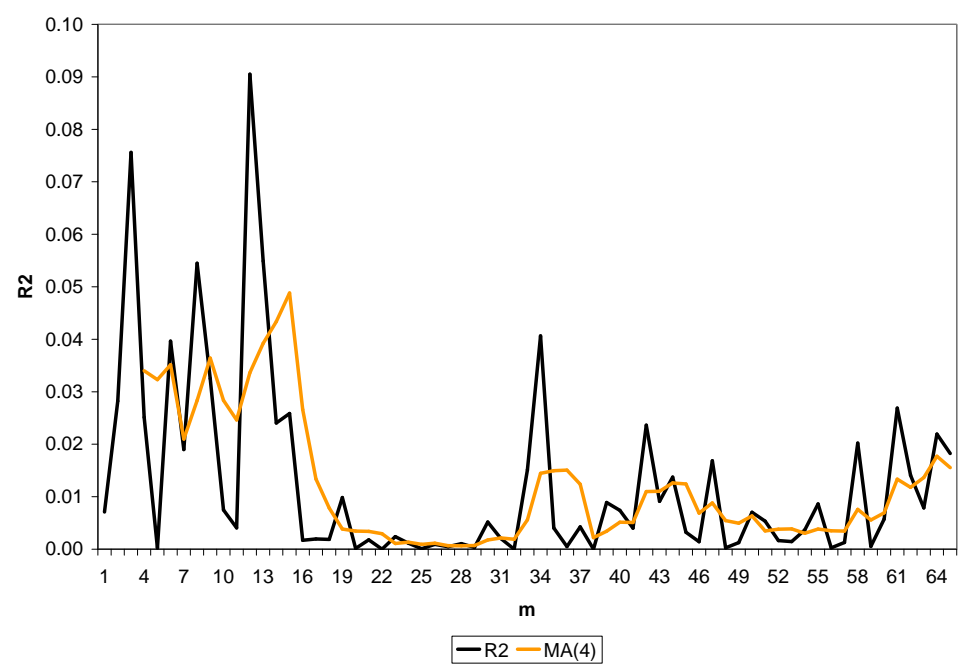

Figure 2: $R^{2}$ of 'Fama regression' for $m=1, \ldots, 65$ 
Figure 2 shows the $R^{2}$ values of the 'Fama regression' for $m=1, \ldots, 65$. Consistent with the finding in the previous literature, the moving average $R^{2}$ values are quite small and do not exceed the value of 0.06 . But an interesting feature is that the $R^{2}$-'s are largest for maturities shorter than a month, which as noted earlier, is the maturity range not covered by conventional forward rate data. For maturities longer than 20 working days, the $R^{2}$ value shrinks almost to zero. However, for maturities at the end of the maturity spectrum covered by our estimations, we see that the $R^{2}$ tends to slightly rise again.

Table 1: Relationship between 'Fama coefficient' and maturity length

\begin{tabular}{lllllll}
\hline$\beta_{(m, 0)}$ & Constant & Maturity & $R^{2}$ & $\mathrm{~N}$ & $\begin{array}{l}\text { Ramsey test } \\
\text { (p-value) }\end{array}$ & $\begin{array}{l}\text { Link test } \\
\text { (p-value) }\end{array}$ \\
\hline & $0.885^{* * *}$ & $-0.028^{* * *}$ & 0.41 & 65 & 0.05 & 0.35 \\
& $(0.171)$ & $(0.004)$ & & & &
\end{tabular}

Notes: Standard errors in parentheses. $* * *, * *$ and $*$ indicates significance at the $1 \%$, $5 \%$ and $10 \%$ level.

To summarize the information which is in the futures data at the daily level, we fit a line through the slope coefficients $\beta_{(m, 0)}$ when plotted against the maturity horizon in days. Table 3 shows the results for the regression of the slope coefficients $\beta_{(m, 0)}$ estimates against a constant and the maturity length $m$. The Ramsey test and the link test are simple methods to assess whether the overall model specification suffers from a wrong functional form. Both tests indicate that the simple linear model assumed here is well specified and that it explains around $35 \%$ of the variation of the slope coefficients. The estimated constant is highly significant and positive. A $t$-test shows that this constant is not significantly different from the value of one. This suggests that we would indeed not reject the expectations hypothesis for futures rates with a very short maturity. Further, we confirm that there exists a significant negative relationship between the maturity horizon of the futures contract and the estimated value for $\beta_{(m, 0)}$. If the time to maturity increases by one (working) day, the estimated slope coefficient decreases by a value of around 0.03 . This implies that the futures premium puzzle (if interpreted as $\left.\beta_{(m, 0)}<0\right)$ only shows up for maturity horizons longer than 31 days. Thus, our estimated threshold of the maturity length above which the forward/futures premium puzzle shows up is much longer compared to the one estimated by Chaboud and Wright (2006), who argue that already for a maturity horizon beyond one day, the slope coefficient turns negative. But our results agree with their evidence that at the short end the expectations hypothesis, or equivalently UIP, is not rejected.

To summarize, our estimation results confirm negative estimated slope coefficients when testing the expectations hypothesis for maturity horizons usually covered by forward exchange rate contracts. However, we find that 
there exists a significant negative relationship between the slope coefficients and the maturity horizon of the futures contracts. If the time to maturity $m$ is small, the rejection of the expectations hypothesis is less decisive and slope coefficients hover around the predicted value. For very long maturities the evidence reported in other research is also in line with the expectations hypothesis. This leads us to conclude that the typical form of the premium correlation when plotted against the maturity horizon is $\mathrm{V}$-shaped. ${ }^{6}$ Why this is the case remains an open issue. But we throw some more light on the issue, by further exploiting the other information in the futures data in the next section.

\section{Outside and Inside Regressions}

The usual argument for differencing the spot and forward rate are their unit root feature and cointegration properties. Instead of differencing with $s_{t-m}$ in equation (1), Pope and Peel (1991) and McCallum (1994) have estimated equation (1) using $s_{t-m-k}$ with $k>0$. For later reference we call this the 'outside regression'. This procedure indeed also ensures that the dependent variable and regressor become stationary as the Dickey-Fuller test confirms. What other merit could this procedure have? By estimating the 'outside regression' one investigates, whether the forward rate at time $t-m$ is able to predict the change of exchange rates between the maturity date $t$ and a date that lies $k$ time periods to the past of the pricing date of that forward rate, $t-m-k$. Thus, the futures market at $t-m$ incorporates the past innovations of the exchange rate. This relationship is also illustrated in the upper panel of Figure 3.

To give an alternative interpretation of the meaning of the 'outside regression', note that equation (1) for $k>0$ can be rewritten as follows:

$$
\begin{gathered}
\left(s_{t}-s_{t-m}\right)+\left(s_{t-m}-s_{t-m-k}\right)= \\
\phi+\beta_{(m, k)}\left[\left(f_{t-m}^{t}-s_{t-m}\right)+\left(s_{t-m}-s_{t-m-k}\right)\right]+\eta_{t-m} .
\end{gathered}
$$

Thus, the 'outside regression' differs from the conventional 'Fama regression' $(k=0)$ in the way that we subtract from both sides of the regression the realized spot exchange rate return between $t-m$ and $t-m-k$. To the time $t-m$, when the futures rate is priced, this exchange rate return is already common knowledge. We call this the 'news part' in the outside regression. A regression of the total return $s_{t}-s_{t-m-k}$ on $f_{t-m}^{t}-s_{t-m-k}$ thus provides information regarding the relative importance of the news part $s_{t-m}-s_{t-m-k}$ versus the forecast part $f_{t-m}^{t}-s_{t-m}$. The lag length $k$ can

\footnotetext{
$\mathrm{V}$.

${ }^{6}$ In this sense, our estimation results shown in Figure 1 illustrate the left wing of the
} 


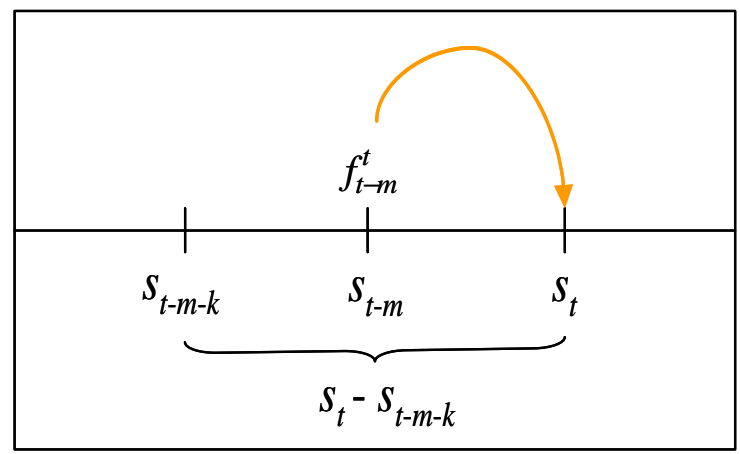

'Outside Regression', k>0

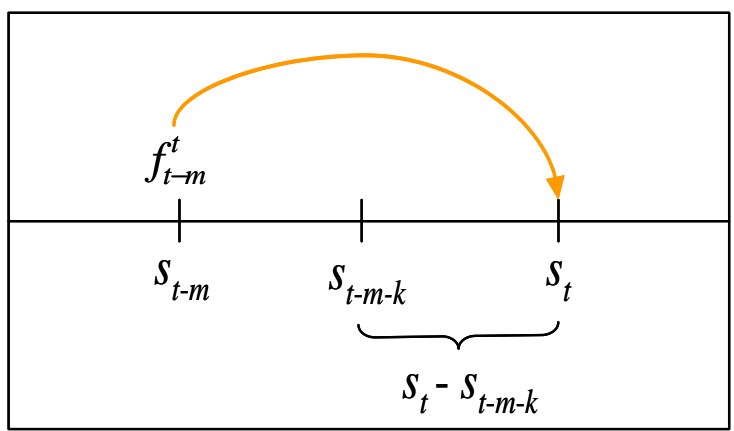

'Inside Regression', k<0

Figure 3: Outside and Inside Regressions

be seen as the 'news advantage' of the forward rate at $t-m$ relative to the spot rate at $t-m-k$. Even though we will show later that the Pope-PeelMcCallum regression has limited value, it nevertheless suggest us a novel take at the data.

The futures data also allow one to do the opposite and move inside the maturity horizon, by taking $k<0$. Note that this is not possible with forward rate data. Thus we also consider a regression of $s_{t}-s_{t-m+q}$ on $f_{t-m}^{t}-s_{t-m+q}$ for $q=-k>0$ and $m>q>0$. For reference this regression is dubbbed the 'inside regression'. To our knowledge there is no published work which has estimated such regressions. Potentially this regression generates some interesting information since it asks whether forex returns during the later part of the maturity horizon are moving as predicted by the futures contract signed much earlier. This becomes clear by regarding the lower part of Figure 3, where the relationship between the dependent and independent variables of the 'inside regression' is described. We can decompose equation 
(1) for $q=-k>0$ as follows:

$$
s_{t}-s_{t-m+q}=\phi+\beta_{(m, q)}\left[\left(f_{t-m}^{t}-s_{t-m}\right)-\left(s_{t-m+q}-s_{t-m}\right)\right]+\eta_{t-m} .
$$

Thus we can potentially deduce whether the futures contract has more to say regarding the earlier or the later day-to-day forex returns over the maturity period.

We run regression (1) for $m=1, \ldots, 65, k=-65, \ldots, 65$ and $m+k>0$ for the pooled data set. ${ }^{7}$ Figure 4 summarizes our estimates of $\beta_{(m, k)} .{ }^{8}$ Thus, we end up with 65 estimated slope coefficients for every value of $k>0$ and with $m-q$ slope coefficients for $k=-q$, since $q<m$. For illustrative reasons, we show only the smallest and largest estimated slope coefficient (the dashed lines) and the mean (the solid line) for every length of the 'news advantage' $k$. Additionally, the vertical bars highlight the time to maturity for which the 'outside regression' can be estimated with conventionally used forward exchange rate data, as it is done by McCallum (1994) and Pope and Peel (1991).

Our estimation results for the outside regressions, to the right of $k=0$, show that the estimated slope coefficient rapidly increases when the news advantage $(k>0)$ increases. With a news advantage of only three days, the mean of the slope coefficients turns to a significantly positive value and converges to the value of one. We also estimated the inside regression equations (1) for $m=1, \ldots, 65$ and $q=64, \ldots, 1$ with $m>q$. The estimation results are plotted to the left of $k=0$ in Figure 4 . One sees that close to $k=0$ there is quite a wide range of different slope values, but the range of the slope coefficients $\beta_{(m, q)}$ rapidly converges towards zero as $q$ gets larger.

In Figure 5 we summarize the estimated $R^{2}$ values of the 'inside' and 'outside regressions'. The dashed lines describe the smallest and largest $R^{2}$ values and the solid line represents the mean $R^{2}$ across the maturity horizons $m$ for every length of the news advantage $k$. We see that for $k \leq 0$, the $R^{2}$ value is very low and does not exceed the value of 0.03 . That means that our 'inside regression' and also the conventional 'Fama regression' explain on average less than three percent of the variation of the exchange rate return $y_{t-m+q}^{t}$, where $m>q \geq 0$. However, for positive 'news advantages' $(k>0)$ we find that the $R^{2}$ value rises substantially. Already for $k=1$, our regression explains on average $10 \%$ of the variation of the exchange rate return $y_{t-m-k}^{t}$. For $k=65$, the maximum $R^{2}$-value is close to one and the mean is about 0.65 .

It is interesting to provide some further interpretation of these results. By running this 'outside regression', one assumes that the market has a 'news

\footnotetext{
${ }^{7}$ The poolability test could not reject in any case the equality of the regressors for all individual currency pairs included in our data set.

${ }^{8} \mathrm{~A}$ t-test confirms that the intercept $\phi$ is not significantly different from zero in all regressions.
} 


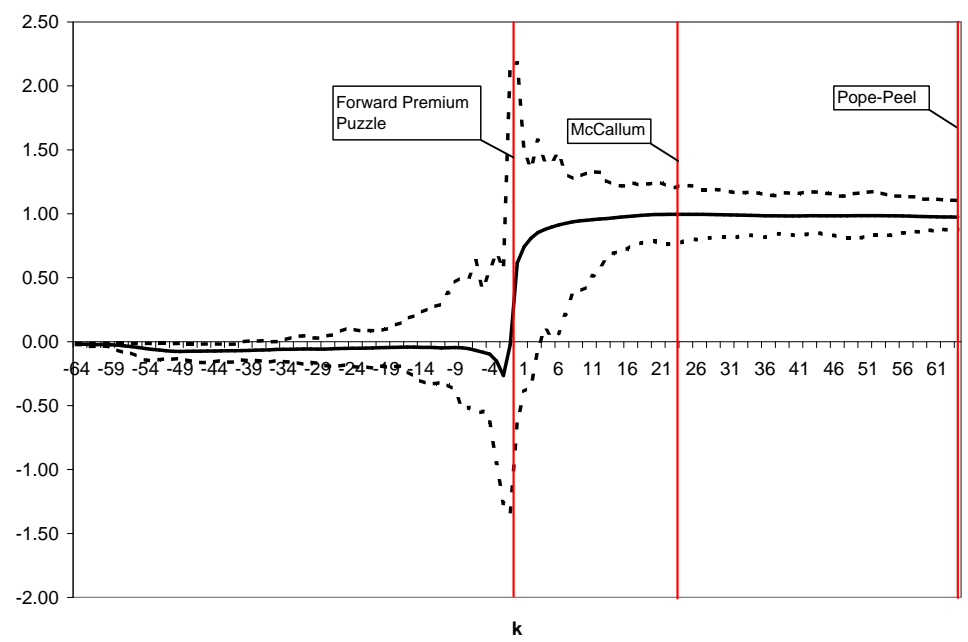

Figure 4: Minimum, maximum and mean of $\beta_{(m, k)}$

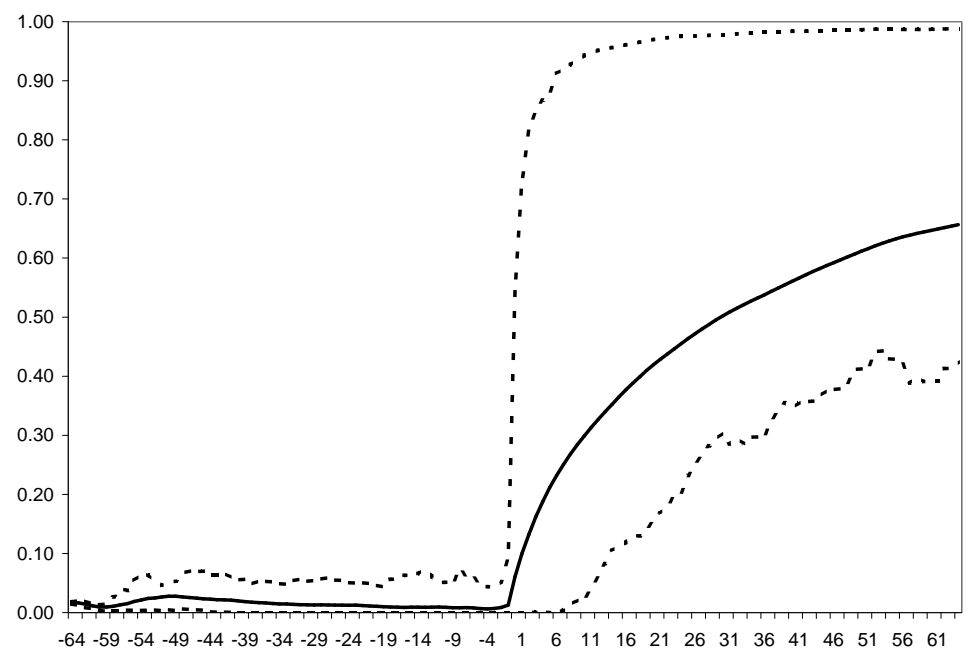

Figure 5: Minimum, maximum and mean $R^{2}$ of in- and outside regressions 
advantage' relative to the spot rate $s_{t-m-k}$. Using monthly and quarterly forward rate data, respectively, McCallum (1994) and Pope and Peel (1991) show that the slope coefficient of the regression, $\beta_{(m, k)}$, is close to unity if the market has a news advantage of one or three months, just as we see with our daily data beyond the horizon of a fortnight. This, however, cannot be taken as evidence that the FPP has disappeared. To show this, note that the slope coefficient for the 'outside regression' can be rewritten as follows:

$$
\begin{aligned}
\beta_{(m, k)}= & \frac{\operatorname{Cov}\left[y_{t-m-k}^{t}, p_{t-m}^{t}+y_{t-m-k}^{t-m}\right]}{\operatorname{Var}\left[p_{t-m}^{t}+y_{t-m-k}^{t-m}\right]} \\
= & \frac{\operatorname{Cov}\left[y_{t-m-k}^{t-m}+y_{t-m}^{t}, p_{t-m}^{t}+y_{t-m-k}^{t-m}\right]}{\operatorname{Var}\left[p_{t-m}^{t}\right]+k \sigma^{2}+\operatorname{Cov}\left[p_{t-m}^{t}, y_{t-m-k}^{t-m}\right]} \\
= & \beta_{(m, 0) \frac{\operatorname{Var}\left[p_{t-m}^{t}\right]}{\operatorname{Var}\left[p_{t-m}^{t}\right]+k \sigma^{2}+\operatorname{Cov}\left[p_{t-m}^{t}, y_{t-m-k}^{t-m}\right]}+} \\
& \frac{\operatorname{Cov}\left[y_{t-m}^{t}, y_{t-m-k}^{t-m}\right]}{\operatorname{Var}\left[p_{t-m}^{t}\right]+k \sigma^{2}+\operatorname{Cov}\left[p_{t-m}^{t}, y_{t-m-k}^{t-m}\right]}+ \\
& \frac{\operatorname{Cov}\left[y_{t-m-k}^{t-m}, p_{t-m}^{t}\right]}{\operatorname{Var}\left[p_{t-m}^{t}\right]+k \sigma^{2}+\operatorname{Cov}\left[p_{t-m}^{t}, y_{t-m-k}^{t-m}\right]}+ \\
& \frac{k \sigma^{2}}{\operatorname{Var}\left[p_{t-m}^{t}\right]+k \sigma^{2}+\operatorname{Cov}\left[p_{t-m}^{t}, y_{t-m-k}^{t-m}\right]},
\end{aligned}
$$

where we use the constant volatility assumption

$$
\operatorname{Var}\left[y_{t-m-k}^{t-m}\right]=k \operatorname{Var}\left[y_{t-m-1}^{t-m}\right]=k \sigma^{2} .
$$

Suppose in addition that the following market efficiency condition applies:

Condition 1 Weak form (level) efficiency assumption holds if the exchange rate innovations and premia from non-overlapping time intervals are uncorrelated:

$$
\operatorname{Cov}\left[y_{t-m}^{t}, y_{t-m-k}^{t-m}\right]=\operatorname{Cov}\left[p_{t-m}^{t}, y_{t-m-k}^{t-m}\right]=0 .
$$

This near random walk behavior of the log exchange rate is a reasonable reflection of the empirical reality (compare e.g. Meese and Rogoff, 1983). Under (6) the expression for the slope estimate $\beta_{(m, k)}$ in (4) simplifies to

$$
\beta_{(m, k)}=\frac{\beta_{(m, 0)}+k \sigma^{2} / \operatorname{Var}\left[p_{t-m}^{t}\right]}{1+k \sigma^{2} / \operatorname{Var}\left[p_{t-m}^{t}\right]} .
$$

It is now easy to see what happens in the regressions. The variance in the innovations $\sigma^{2}$ is large relative to the variance of the premium $\operatorname{Var}\left[p_{t-m}^{t}\right]$, so when $k$ increases the $k \sigma^{2} / \operatorname{Var}\left[p_{t-m}^{t}\right]$ terms in the numerator and denominator quickly start to dominate and pull the value of $\beta_{(m, k)}$ towards $1 .^{9}$ This

\footnotetext{
${ }^{9}$ Note that $\partial \beta_{(m, k)} / \partial k>0$ and $\partial^{2} \beta_{(m, k)} /(\partial k)^{2}<0$.
} 
shows that the relative sizes of the two covariance terms $\operatorname{Cov}\left[y_{t-m}^{t}, y_{t-m-k}^{t-m}\right]$ and $\operatorname{Cov}\left[y_{t-m-k}^{t-m}, p_{t-m}^{t}\right]$ in (4) are indeed unimportant. ${ }^{10}$ What one learns from these regressions is that there is news dominance as $\sigma^{2} / \operatorname{Var}\left[p_{t-m}^{t}\right]$ is relatively large, and the market is efficient in the sense that $\operatorname{Cov}\left[y_{t-m}^{t}, y_{t-m-k}^{t-m}\right]$ and $\operatorname{Cov}\left[y_{t-m-k}^{t-m}, p_{t-m}^{t}\right]$ are small. But note that this is not incompatible with $\beta_{(m, 0)}<0$, so that the premium puzzle is still present in the background.

Similarly, we can interpret the inside regressions. By running this 'inside regression' one investigates, whether the forward rate at time $t-m$ is able to predict the change of exchange rates between the maturity date $t$ and a date that lies $q$ days into the future of the pricing date $t$ of the futures contract, $t-m+q$. The estimated slope coefficient of the 'inside regression' is:

$$
\begin{gathered}
\beta_{(m, q)}=\frac{\operatorname{Cov}\left[y_{t-m+q}^{t}, f_{t-m}^{t}-s_{t-m+q}\right]}{\operatorname{Var}\left[f_{t-m}^{t}-s_{t-m+q}\right]} \\
=\frac{\operatorname{Cov}\left[y_{t-m}^{t}-y_{t-m}^{t-m+q}, p_{t-m}^{t}-y_{t-m}^{t-m+q}\right]}{\operatorname{Var}\left[p_{t-m}^{t}-y_{t-m}^{t-m+q}\right]} \\
=\frac{\beta_{(m, 0)} \operatorname{Var}\left[p_{t-m}^{t}\right]-\operatorname{Cov}\left[y_{t-m}^{t}, y_{t-m}^{t-m+q}\right]-\operatorname{Cov}\left[y_{-m}^{t-m+q}, p_{t-m}^{t}\right]+\operatorname{Var}\left[y_{t-m}^{t-m+q}\right]}{\operatorname{Var}\left[p_{t-m}^{t}\right]+q \sigma^{2}-2 \operatorname{Cov}\left[y_{t-m}^{t-m+q}, p_{t-m}^{t}\right]},
\end{gathered}
$$

where again we made use of the constant volatility assumption (5). Simplifying further on the basis of efficient market condition (6), gives

$$
\begin{aligned}
\beta_{(m, q)} & =\frac{\beta_{(m, 0)} \operatorname{Var}\left[p_{t-m}^{t}\right]-\operatorname{Cov}\left[y_{t-m}^{t-m+q}, p_{t-m}^{t}\right]}{\operatorname{Var}\left[p_{t-m}^{t}\right]+q \sigma^{2}-2 \operatorname{Cov}\left[y_{t-m}^{t-m+q}, p_{t-m}^{t}\right]} \\
& =\frac{\beta_{(m, 0)}-\operatorname{Cov}\left[y_{t-m}^{t-m+q}, p_{t-m}^{t}\right] / \operatorname{Var}\left[p_{t-m}^{t}\right]}{1+q \sigma^{2} / \operatorname{Var}\left[p_{t-m}^{t}\right]-2 \operatorname{Cov}\left[y_{t-m}^{t-m+q}, p_{t-m}^{t}\right] / \operatorname{Var}\left[p_{t-m}^{t}\right]} .
\end{aligned}
$$

Equation (9) reveals two interesting facts.

First, we see that independent of whether the expectations hypothesis holds $\left(\beta_{(m, 0)}=1\right)$, the slope coefficient $\beta_{(m, q)}$ is pulled towards 0 as $q$ becomes larger. As is the case for the outside regression, this effect depends on the magnitude of the news dominance feature $q \sigma^{2} / \operatorname{Var}\left[p_{t-m}^{t}\right]$. But in addition $\beta_{(m, q)}$ now depends on magnitude of another term

$$
\operatorname{Cov}\left[y_{t-m}^{t-m+q}, p_{t-m}^{t}\right] / \operatorname{Var}\left[p_{t-m}^{t}\right] .
$$

\footnotetext{
${ }^{10} \mathrm{McCallum}$ explains the estimation result as follows. He notes that the 'outside regression' $(k>0)$ differs from the conventional regression $(k=0)$ in the way that the exchange rate innovation $y_{t-m-k}^{t-m}$ is added to both sides of the regression. If the variance of $y_{t-m-k}^{t-m}$ is large, the estimated slope coefficient is driven to unity.
} 
Nevertheless, as the Figure 4 for the inside regression show, this second term is also relatively small as $\beta_{(m, q)}$ rapidly converges towards zero for larger values of $q$.

Second, in contrast to the expression (7) for the outside regression, we see that (9) contains an extra term $\operatorname{Cov}\left[y_{t-m}^{t-m+q}, p_{t-m}^{t}\right]$ in the numerator and denominator. Thus for small values of $q$ this slope estimate provides extra information. In fact, by using the definition of $\beta_{(m, 0)}$ one can write (9) differently, to isolate the extra information more clearly

$$
\beta_{(m, q)}=\frac{\operatorname{Cov}\left[y_{t-m+q}^{t}, p_{t-m}^{t}\right]}{\operatorname{Var}\left[p_{t-m}^{t}\right]+q \sigma^{2}-2 \operatorname{Cov}\left[y_{t-m}^{t-m+q}, p_{t-m}^{t}\right]} .
$$

Writing $\beta_{(m, q)}$ in this way shows that it contains the covariance of the daily forex returns with the premium over the early part of the maturity horizon in the denominator, and the covariance of the daily forex returns with the premium over the later part of the maturity horizon in the numerator. Thus $\beta_{(m, q)}$ is indeed of interest as it contains information on the question whether some of the daily forex returns during the early or the later parts of the maturity horizon are moving as predicted by the futures contract. Since we already know that the $\beta_{(m, 0)}$ is negative for larger horizons $m$, it is of interest to know which parts of the daily forex returns are driving this result. This makes $\beta_{(m, q)}$ of interest in principle, but it is not the most effective way of reporting this information since it is a combination of these two correlations and the other two moments $\sigma^{2}$ and $\operatorname{Var}\left[p_{t-m}^{t}\right]$.

\section{A Decomposition and its Information}

The two covariances from (10) are also part of the standard premium regression coefficient $\beta_{(m, 0)}$. The $\beta_{(m, 0)}$ coefficient can be simply decomposed as follows

$$
\begin{aligned}
\beta_{(m, 0)}= & \frac{\operatorname{Cov}\left[y_{t-m}^{t}, p_{t-m}^{t}\right]}{\operatorname{Var}\left[p_{t-m}^{t}\right]}= \\
& \frac{\operatorname{Cov}\left[y_{t-m+q}^{t}, p_{t-m}^{t}\right]}{\operatorname{Var}\left[p_{t-m}^{t}\right]}+\frac{\operatorname{Cov}\left[y_{t-m}^{t-m+q}, p_{t-m}^{t}\right]}{\operatorname{Var}\left[p_{t-m}^{t}\right]},
\end{aligned}
$$

which shows that the two covariances are not independent from $\beta_{(m, 0)}$. But since we have an interest in both covariances separately, it is more expedient to directly calculate these covariances with the help of the futures rates. A plot of these covariances scaled by $\operatorname{Var}\left[p_{t-m}^{t}\right]$ for $m=65$ and $q=1, \ldots, 64$ is given in Figure 6. Note that the two scaled covariances add up to $\beta_{(m, 0)}$.

The graphs show that $\operatorname{Cov}\left[y_{t-m}^{t-m+q}, p_{t-m}^{t}\right] / \operatorname{Var}\left[p_{t-m}^{t}\right]$ is positive for $q$ close to 1 . This indicates that the daily exchange rate returns during the 


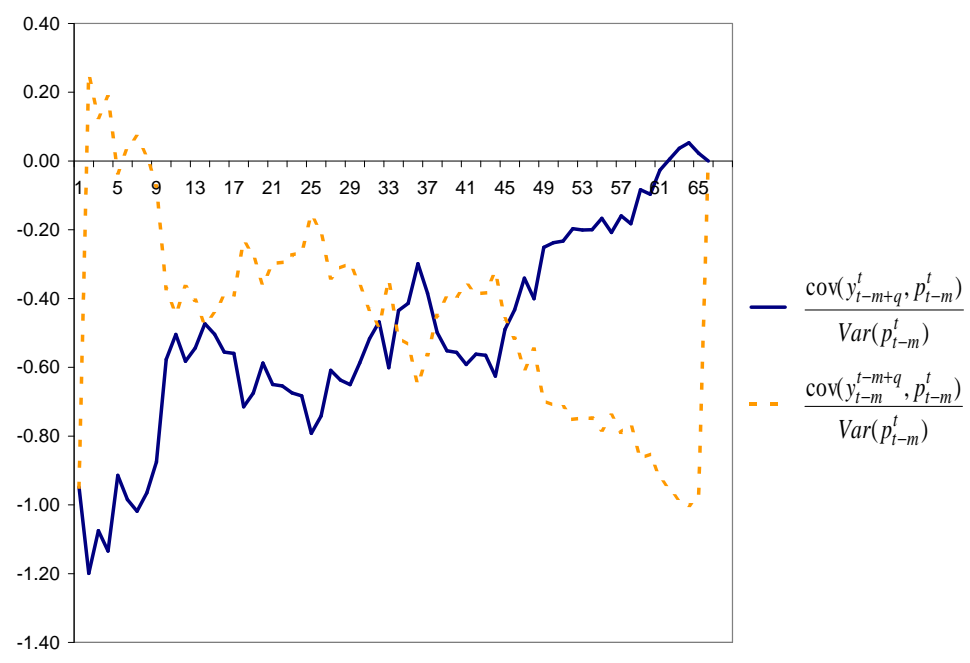

Figure 6: Decomposition of Covariances for $m=65$

early parts of the maturity horizon move in line with the premium prediction, but that they go in reverse during the second half. Thus, not only the ability of the futures rate priced at time $t-m, f_{t-m}^{t}$, to predict the forex innovation between $t$ and $t-m, y_{t-m}^{t}$, increases if $m$ becomes small, as was shown previously. But within a given fixed maturity period $t-m$, the earlier (daily) exchange rate returns $y_{t-m}^{t-m+q}$ move in line with the premium $p_{t-m}^{t}$, while the later forex returns $y_{t-m+q}^{t}$ have the tendency to move in the opposite direction of $p_{t-m}^{t}$. Hence, the negativity in $\beta_{(m, 0)}$ is caused by the later moves in the forex returns. In other words, let $x$ be a subset of the time period between $t-m$ and $t$ and $y_{x}$ be the the exchange rate change during the subperiod $x$. Our estimation results suggest that the larger $x$, the more negative becomes the covariance between $y_{x}$ and the futures premium $p_{t-m}^{t}$. This seems to be a novel finding and adds to our previous finding that the expectations hypothesis holds for shorter maturities.

\section{Conclusion}

The FPP is the medium term (mostly) negative correlation between the forward premium and the realized exchange rate return at maturities of a month and beyond. This paper contributes by using futures data instead of forwards to complete the maturity spectrum at the shorter term (multi-) day level. Our estimation results confirm negative slope coefficients when testing the expectations hypothesis for maturity horizons usually covered by forward exchange rate contracts at the monthly frequency. However, we 
find that there exists a significant negative relationship between the slope coefficients and the maturity horizon of the futures contracts. If the time to maturity $m$ is short, the rejection of the expectations hypothesis is less decisive and slope coefficients hover around the predicted value of one. This extends the recent intra-day evidence. For a maturity of a month, say, the daily exchange rate returns at the beginning of the month behave in line with the predictions of the expectations hypothesis, while the later dayto-day forex changes run in the opposite direction. In the end the latter dominate the total exchange rate return over the entire month. For very long maturities the evidence reported in other recent research is also in line with the expectations hypothesis. Thus it appears that the market in the beginning follows the predictions of the expectations hypothesis, but reverses itself, only to come back to this once again after a period of years. This leads us to conclude that the typical form of the premium correlation when plotted against the maturity horizon is $\mathrm{V}$-shaped. The $\mathrm{V}$-shape is reminiscent of similar mean reversion behavior of stock market returns. Why these reversals take place is less clear. Popular explanations like irrationality and learning hypothesis and the (time-varying) risk premium hypothesis do not square well with this evidence.

The empirical evidence presented here thus poses a challenge for economic theory. The attempts to reconcile the differences in the estimation results at very short, short (this paper), medium term and long maturity horizons are scarce. Furthermore, these reconciliations are incomplete in the sense that they either focus on explaining the difference between the estimation results at the very short and medium term maturity horizons or at the medium term and long maturity horizons. But as of today these theories do not explain the results found for the complete maturity spectrum. Chinn and Meredith (2004) use a macroeconomic model which enriches the framework of McCallum (1994) by incorporating a reaction function that causes interest rates to respond to innovations in output and inflation. Their simulations show that estimates of the UIP regression generate a forward bias at medium term horizons but not at long horizons, which is consistent with one part of the empirical findings described above. They conclude that in the long-run the model's fundamentals play a more important role, while in the short term interest differentials are biased predictors of exchange rate movements due to monetary policy interventions, which gives rise to such poorly understood phenomena like the carry trade.

Bacchetta and Wincoop (2007) show that the FPP can be explained by the fact that investors revise their FX portfolio positions infrequently. Since portfolio adjustments become more frequent with an increase in the maturity horizon, this explains why FPP shows up for shorter but not for longer maturities. However, the recent results of Chaboud and Wright (2005), who report that UIP holds for very short maturities but not for longer maturities, and our short term results pose a challenge to the latter explana- 
tions. Chaboud and Wright (2005) interpret their finding as evidence for the existence of a risk premium, which shrinks to zero for sufficiently short maturities. However, this interpretation seems to be challenged by the finding of Chinn and Meredith (2004), who find that UIP holds in the long run. Clearly the V-shape requires further empirical scrutiny and theoretical analysis.

\section{References}

[1]Alexius, A.(2001). "Uncovered Interest Parity Revisited", Review of International Economics 9, 505-517.

[2]Bacchetta, P. and van Wincoop, E (2006). "Incomplete Information Processing: A Solution to the Forward Discount Puzzle", mimeo.

[3]Bacchetta, P. and van Wincoop, E (2007). "Random Walk Expectations and the Forward Discount Puzzle", mimeo.

[4]Baillie, R.T. and Bollerslev, T. (1989). "Common Stochastic Trends in a System of Exchange Rates", Journal of Finance 44, 167-181.

[5]Baillie, R.T. and Bollerslev, T. (2000). "The Forward Premium Anomaly is not as bad as you think", Journal of International Money and Finance 19, 471-488.

[6]Bekaert, G. and Hodrick, R.J. (1993). "On Biases in the Measurement of Foreign Exchange Risk Premiums", Journal of International Money and Finance 12, 115138.

[7]Bilson, J.F.O. (1981). "The 'Speculative Efficiency' Hypothesis", Journal of Business 54, 435-451.

[8]Chaboud, A.P. and Wright, J.H. (2005). "Uncovered Interest Parity, it works, but not for long", Journal of International Economics 66(2), 349-362.

[9] Cavaglia, S., Verschoor, W. and Wolff, C. (1994). "On the Biasedness of Forward Foreign Exchange Eates: Irrationality or Risk Premia?", Journal of Business 67, $321-343$.

[10]Chang, C.W. and J.S.K. (1990). "Forward and future prices: Evidence from the foreign exchange markets", Journal of Finance 45, 1333-35.

[11]Chinn, M.D. (2006). "The (partial) Rehabilitation of the Interest Parity in the Floating Rate Era: Longer Horizons, Alternative Expectations, and Emerging Markets", Journal of International Money and Finance 25, 7-21.

[12]Chinn, D.C. and Meredith, G. (2004). "Monetary Policy and Long Horizon Uncovered Interest Parity", IMF Staff Papers 51(3), 409-430.

[13]Clarida, R.H. and Taylor, M.P. (1997). "The Term Structure of Forward Exchange Premiums and the Forecastability of Spot Exchange Rates: Correcting the Errors", The Review of Economics and Statistics 79, 353-361.

[14]Engel, C. (1996). "The Forward Discount Anomaly and the Risk Premium: A Survey of Recent Evidence", Journal of Empirical Finance 3, 123-192.

[15]Evans, M.D.D. and Lewis, K. (1995). "Do Long-Term Swings in the Dollar Affect Estimates of the Risk Premium?", The Review of Financial Studies 8, 
709-742.

[16]Fama, F.E. (1984). "Forward and Spot Exchange Rates", Journal of Monetary Economics 14, 319-338.

[17]Fama, F.E. (2006). "The Behavior of Interest Rates", Review of Financial Studies 19, 359-379.

[18]Fama, F.E. and Bliss, R.R. (1987). "The Information in Long-Maturity Forward Rates", American Economic Review 77, 680-92.

[19]Frankel, J., Chinn, M. (1993). "Exchange Rate Expectations and the Risk Premium: Test for a Cross Section of 17 Currencies", Review of International Economics 1, 136-144.

[20]Frenkel, J.A. (1977). "The Forward Exchange Rate, Expectations and the Demand for Money: the German Hyperinflation", American Economic Review 67, 653-670.

[21]Frenkel, J.A. (1980). "Exchange Rates, Prices and Money: Lessons from the 1920s", American Economic Review, Papers and Proceedings, 70, 235-242.

[22]Froot, K.A. and Frankel, A. (1989). "Forward Discount Bias: Is it an Exchange Risk Premium?", The Quarterly Journal of Economics 104, 139-161.

[23]Froot, K.A. and Frankel, A. (1990). "Anomalies: Foreign Exchange", Journal of Economic Perspectives 4, 179-92.

[24]Gourinchas, P.-O. and Tornell, A. (2004). "Exchange Rate Puzzles and Distorted Beliefs", Journal of International Economics 63, 303-333.

[25]Hodrick, R.J. and Srivastava, S. (1986). "The Covariation of Risk Premiums and Expected Future Spot Exchange Rates", Journal of International Finance 5, 5-21.

[26]Hsieh, D.A. (1984). "Tests of Rational Expectations and no Risk Premium in Forward Exchange Markets", Journal of International Economics 17, 173-84.

[27]Hull, J. C. (2006). Options, Futures, and other Derivatives. Pearson Prentice Hall.

[28]Krasker, W. (1980). "The Peso Problem in Testing the Efficiency of Forward Exchange Markets", Journal of Monetary Economy 6, 269-276.

[29]Levich, R. (1978). "Test of the Forecasting Models and Market Efficiency in the International Money Market", in The Economics of Exchange Rates, edited by J.A. Frenkel and H.G. Johnson, Addison-Wesley, 128-158.

[30]Levich, R.M. (1985). "Empirical Studies of Exchange Rates: Price Behavior, Rate Determination and Market Efficiency", in Handbook of International Economics Vol. II, edited by G. Grossman and K. Rogoff, 979-1040.

[31]Lewis, K.K. (1995). "Puzzles in International Financial Markets", in Handbook of International Economics, Vol.III, edited by G. Grossman and K. Rogoff, 19131971.

[32]Mark, N.C. (1985). "On Time Varying Risk Premia in the Foreig Exchange Market", Journal of Monetary Economics 16, 3-18.

[33]Mark, N.C., Wu, Y. and Hai, W. (1997). "Understanding Spot and Forward Exchange Rate Regressions", Journal of Applied Econometrics 12, 715-734.

[34]Mark, N.C., Wu, Y. (1998). "Rethinking Deviations from Uncovered Interest 
Parity: The Role of Covariance Risk and Noise", The Economic Journal 108.

[35]McCallum, B.T. (1994). "A Reconsideration of the Uncovered Interest Parity Relationship", Journal of Monetary Economics 33, 105-132.

[36]Meese, R. A. and K. Rogoff (1983). "Empirical exchange rate models of the seventies: Do they fit out-of-sample?", Journal of International Economics 14, $3-24$.

[37]Meese, R., Singleton, K.J. (1982). "On Unit Roots and the Empirical Modeling of Exchange Rates", Journal of Finance 37, 1029-1035.

[38]Newbold, P., Wohar, M., Rayner, T., Kellard, N. and Ennew, C. (1998). "Two puzzles in the Analysis of Foreign Exchange Market Inefficiency", International Review of Financial Analysis 7, 95-111.

[39]Polakoff, M.A. and Grier, P.C. (1991). "A comparison of foreign exchange forward and futures prices", Journal of Banking and Finance 15, 1057-80.

[40]Pope, P.F. and Peel, D. (1991). "Forward Foreign Exchange Rates and Risk Premia-A Reappraisal", Journal of International Money and Finance 10, 443456. 